\title{
Characterization of promoter sequence of toll-like receptor genes in Vechur cattle
}

\author{
R. Lakshmi ${ }^{1}$, K. K. Jayavardhanan ${ }^{1}$ and T. V. Aravindakshan ${ }^{2}$
}

1. Department of Veterinary Biochemistry, College of Veterinary and Animal Sciences, Thrissur, Kerala, India;

2. Centre for Advanced Studies in Animal Genetics and Breeding, College of Veterinary and Animal Sciences, Thrissur, Kerala, India.

Corresponding author: R. Lakshmi, e-mail: lakshmivetbio@gmail.com,

KKJ: jayavardhanan@kvasu.ac.in, TVA: aravindakshantv@kvasu.ac.in

Received: 29-02-2016, Accepted: 18-05-2016, Published online: 21-06-2016

doi: 10.14202/vetworld.2016.626-632 How to cite this article: Lakshmi R, Jayavardhanan KK, Aravindakshan TV (2016) Characterization of promoter sequence of toll-like receptor genes in Vechur cattle, Veterinary World, 9(6): 626-632.

\begin{abstract}
Aim: To analyze the promoter sequence of toll-like receptor (TLR) genes in Vechur cattle, an indigenous breed of Kerala with the sequence of Bos taurus and access the differences that could be attributed to innate immune responses against bovine mastitis.

Materials and Methods: Blood samples were collected from Jugular vein of Vechur cattle, maintained at Vechur cattle conservation center of Kerala Veterinary and Animal Sciences University, using an acid-citrate-dextrose anticoagulant. The genomic DNA was extracted, and polymerase chain reaction was carried out to amplify the promoter region of TLRs. The amplified product of TLR2, 4, and 9 promoter regions was sequenced by Sanger enzymatic DNA sequencing technique.

Results: The sequence of promoter region of TLR2 of Vechur cattle with the B. taurus sequence present in GenBank showed $98 \%$ similarity and revealed variants for four sequence motifs. The sequence of the promoter region of TLR4 of Vechur cattle revealed $99 \%$ similarity with that of B. taurus sequence but not reveals significant variant in motifregions. However, two heterozygous loci were observed from the chromatogram. Promoter sequence of TLR9 gene also showed $99 \%$ similarity to B. taurus sequence and revealed variants for four sequence motifs.
\end{abstract}

Conclusion: The results of this study indicate that significant variation in the promoter of TLR2 and 9 genes in Vechur cattle breed and may potentially link the influence the innate immunity response against mastitis diseases.

Keywords: mastitis, promoter, sequence, toll-like receptor, Vechur breed.

\section{Introduction}

Toll-like receptors (TLRs) are critical sensors of microbial attack and effectors of the TLR dependent innate defense mechanism, enabling the host to eliminate pathogens that otherwise would cause disease or mortality [1]. TLRs recognize a wide variety of pathogen-associated molecular patterns (PAMPs) from bacteria, viruses, and fungi as well as some of the host molecules which in turn trigger intracellular signal transduction cascades that result in the expression of pro-inflammatory cytokines, chemokines, and antiviral molecules [2]. So far, 13 TLRs have been identified in mammals of which 10 TLRs are known to occur in cattle, and the expression of TLR transcripts varies among different mammalian species. Among the members of TLR family, TLR2, 4, and 9 play an essential role in both innate immunity and adaptive immune response by ligand recognition and signal transduction. TLR2 is essential for the recognition of a variety of PAMPs from Gram-positive bacteria,

Copyright: Lakshmi, et al. Open Access. This article is distributed under the terms of the Creative Commons Attribution 4.0 International License (http://creativecommons.org/licenses/ by/4.0/), which permits unrestricted use, distribution, and reproduction in any medium, provided you give appropriate credit to the original author(s) and the source, provide a link to the Creative Commons license, and indicate if changes were made. The Creative Commons Public Domain Dedication waiver (http:// creativecommons.org/publicdomain/zero/1.0/) applies to the data made available in this article, unless otherwise stated. including bacterial lipoproteins, lipomannans, and lipoteichoic acids, whereas TLR4 is predominantly activated by lipopolysaccharides [3]. TLR9 is a pattern recognition receptor that plays a key role in cell survival through recognition of various bacterial components including unmethylated CpG-DNA [4]. The expression of TLR 2, 4, and 9 are critical sensors of innate defense against bacterial infection.

Vechur cattle, a rare breed of Bos indicus, are an indigenous breed of Kerala, and it is the smallest cattle breed in the world. They are well adapted for the hot, humid tropical climate of Kerala and are high disease resistant. In dairy industry, mastitis is considered to be one of the expensive diseases and a major economic issue for dairy farmers [5]. In India, the economic loss due to mastitis is about 2500 million per annum. Vechur breeds are not prone to mastitis. Characterization of factors involved in the innate immune system of this breed might provide an insight into the mechanisms involved in the disease resistance.

The promoter region of a gene, through binding of a specific transcription factor, is directly involved in gene transcription initiation. Therefore, sequence variation in this region may alter transcription factor binding sites, which in turn can affect gene expression and exert biological impacts [6]. Given their key role as sentinels of the innate immune defense, TLR structure, and function are tightly regulated. Numerous attempts 
have been made to identify variation affecting TLR structural genes, but studies on genetic variation in the promoter region of TLRs gene are relatively rare, and their contribution to disease remains unclear. In this study, promoter sequence of TLR2, 4, and 9 genes in Vechur cattle breed was examined and accessed the differences that could be attributed to innate immune responses against bovine mastitis.

\section{Materials and Methods \\ Ethical approval}

The study was approved by the committee framed for the research by the university authority. Adequate measures were taken to minimize pain or discomfort in accordance with the International Animal Ethics Committee.

\section{Experimental animals and DNA extraction}

Blood samples were collected using acid-citrate-dextrose anticoagulant from Jugular vein of Vechur cattle, maintained at Vechur cattle conservation center of Kerala Veterinary and Animal Sciences University. The genomic DNA was extracted by phenol-chloroform method. The DNA concentration was assessed by NanoDrop (Thermo Scientific, USA) spectrophotometer, and the purity was confirmed by measuring absorbance at $260 \mathrm{~nm}$ and $280 \mathrm{~nm}$, followed by quality of the DNA was also assessed by agarose gel (1\%) electrophoresis.

\section{Primer designing and polymerase chain reaction (PCR) amplifications}

Primers used to amplify the promoter region of TLR2 (AC_000174), TLR4 (AC_000165), and TLR9 (AC_000179) genes in Vechur cattle were designed from Bos taurus sequences available in National Centre for Biotechnology Information (NCBI) database. Primers were designed using an online tool from NCBI, Primer-BLAST. The designed forward and reverse primers were custom synthesized at SigmaAldrich India (Table-1). The primers were reconstituted in nuclease-free water to a concentration of $10 \mathrm{p} \mathrm{M} / \mu 1$.

The promoter regions of TLRs were amplified through PCR. $20 \mu \mathrm{L}$ of PCR were carried out in $0.2 \mathrm{~mL}$ PCR tube and each tube contained $2 \mu \mathrm{L}$ of genomic DNA (50 ng) as template, $1 \mu 1$ of each forward primer and reverse primer $(10 \mathrm{pM} / \mu \mathrm{l}), \times 2$ concentration of $10 \mu 1$ of PCR reaction mix (contain dNTPs- $0.4 \mathrm{mM}$ each, Taq polymerase- $0.05 \mathrm{U} / \mu 1$, magnesium chloride- $4 \mathrm{mM}$ ), and $6 \mu \mathrm{L}$ of nuclease-free water. PCR conditions followed for amplification of promoter region of TLR2, 4, and 9 genes are presented in Table-2. Amplified PCR products were separated by agarose gel electrophoresis (1.5\%) and visualized by ethidium bromide staining.

\section{Sequencing and analysis}

The purified PCR products of the promoter regions of TLR2, 4, and 9 genes were commercially sequenced by Sanger's enzymatic DNA sequencing
Table-1: Primers designed for TLR promoter regions from NCBI databank sequences.

\begin{tabular}{|c|c|c|}
\hline Target & Primer sequence $\left(5^{\prime} \rightarrow 3^{\prime}\right)$ & Size \\
\hline \multirow[t]{2}{*}{$\begin{array}{l}\text { Promoter } \\
\text { region of } \\
\text { TLR2 }\end{array}$} & Forward TGTGGCATCTCTCGTTCCT & $934 \mathrm{bp}$ \\
\hline & Reverse CTGGTTACTCTGCTCCCTGA & \\
\hline \multirow[t]{2}{*}{$\begin{array}{l}\text { Promoter } \\
\text { region of } \\
\text { TLR4 }\end{array}$} & Forward GTCCCTTGCTCTATCAGGCA & $898 \mathrm{bp}$ \\
\hline & Reverse ATGCTGTCCCCTTGGCTTAT & \\
\hline $\begin{array}{l}\text { Promoter } \\
\text { region of } \\
\text { TLR9 }\end{array}$ & Forward CTGGGGTAGGGGCTITATAAGA & $1005 \mathrm{bp}$ \\
\hline & Reverse CCATCTGTCACATCCCACGT & \\
\hline
\end{tabular}

TLR=Toll-like receptor

Table-2: PCR program for amplification of TLR promoter region in Vechur cattle.

\begin{tabular}{ll}
\hline Steps & Temperature and time \\
\hline Initial denaturation & $95^{\circ} \mathrm{C}$ for 3 min \\
Denaturation & $95^{\circ} \mathrm{C}$ for $30 \mathrm{~s}$ \\
Annealing & $53.2^{\circ} \mathrm{C}$ for $30 \mathrm{~s}$ for TLR2 \\
& $56.0^{\circ} \mathrm{C}$ for $30 \mathrm{~s}$ for TLR4 \\
& $53.0^{\circ} \mathrm{C}$ for $30 \mathrm{~s}$ for TLR9 \\
Extension & $72^{\circ} \mathrm{C}$ for 1 min \\
& Step 2 to 4 set for 35 cycles \\
Final extension & $72^{\circ} \mathrm{C}$ for 5 min
\end{tabular}

$\mathrm{TLR}=$ Toll-like receptor, $\mathrm{PCR}=$ Polymerase chain reaction

technique. The nucleotide sequences for the promoter of TLR2, 4, and 9 genes were submitted to GenBank. Sequence alignment of Vechur breed promoter regions of TLR2, 4, and 9 genes with B. taurus sequences was performed using CLUSTALW.

\section{Results and Discussion}

Bovine mastitis, defined as an inflammation of the mammary gland, is generally considered the most economically imposing diseases of dairy cattle. Financial losses due to mastitis occur for animals experiencing both subclinical and clinical disease. Subclinical mastitis is the most economically important form of mastitis because of long-term reductions in milk yield. Vechur cattle breed found in Kerala state are known for less susceptible to mastitis than any other cattle breeds. The marked differences in susceptibility to mastitis predict that there is substantial variation in the efficiency of the antimicrobial defense within the cattle breeds. Yet, the mechanisms underlying exaggerated or attenuated response of Vechur breed to mastitis remain unclear. As TLRs are essential for innate immunity, understanding the genetic basis of varied TLRs receptor expression and function is of great importance for the many biological end points that depend on TLRs signaling. The promoter region of TLRs plays a key role in the transcription of genes. Promoter region consists of various consensus sequences, capable of regulating the rate of transcription by inducing or suppressing the respective genes. TLR2, 4, and 9 are reported as critical 
sensors of innate defense against bovine mastitis [3]. In this study, sequence variation of these TLRs promoter region in Vechur breed was examined for the important regulatory motifs that might influence the expression of TLR genes and innate immune response dynamics against bovine mastitis.

The promoter region of TLR2, 4, and 9 of Vechur cattle was successfully amplified using specific primer pairs. The sizes of amplified products were verified using agarose gel electrophoresis (Figure-1). Nucleotide sequences for promoter regions of these TLRs genes were deposited in GenBank and assigned with the following accession numbers: TLR2 promoter, KR559022.1; TLR4 promoter, KR559023.1; TLR4 promoter, KR559024.1.

TLR2 is essential for the recognition of a variety of PAMPs from Gram-positive bacteria. TLR2 forms heterodimers with TLR1 or TLR6, each dimer having different ligand specificity thus increasing its binding receptors. TLR2 mRNA expression was strongly increased in mammary tissue in cattle. The promoter sequences of TLRs genes in Vechur cattle were assessed with $B$. taurus for the important sequence motifs, consensus sequence, and their functions. The sequence of promoter region of TLR2 of Vechur cattle with the B. taurus sequence present in GenBank showed 98\% similarity and revealed variants for four sequence motifs. All of these motifs were located in sequences with a high degree of homology

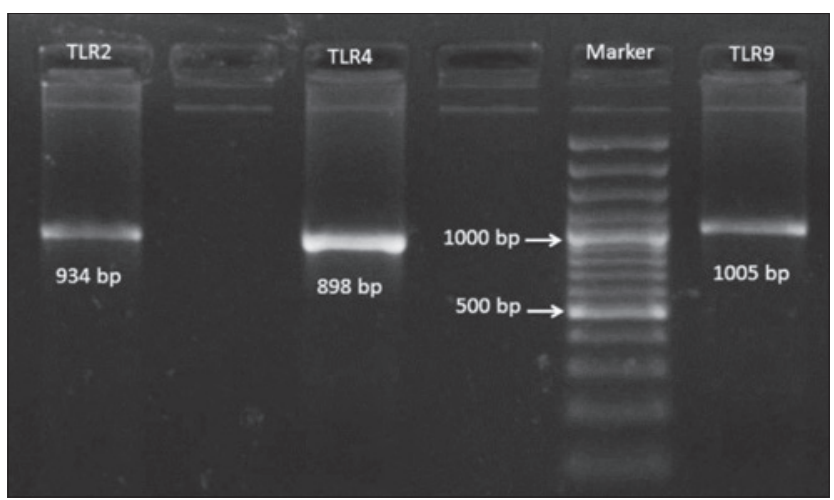

Figure-1: Polymerase chain reaction product size of tolllike receptor 2,4 , and 9 promoter region. to possible transcription factor binding site. The important sequence motif and variations observed in Vechur cattle with that of $B$. taurus sequence are listed in Table-3 and also highlighted in Figure-2.

A consensus TATA boxwas observed in the promoter sequence of TLR2 gene of Vechur, which might consider as the core promoter for transcription initiation [7], to which RNA polymerase II binds is found to be present in the region between -726 and $-723 \mathrm{bp}$. In addition, TATA-like sequences such as TATAA also present in the region of -85 to $-81 \mathrm{bp}$ and -752 to -748 bp with one single nucleotide polymorphism (SNP) at bp -751 in Vechur cattle. The AT-rich region of TATA box can facilitate easy unwinding of DNA due to weak interaction between the bases than GC during initiation of transcription.

Cyclic adenosine monophosphate (cAMP) responsive elements (CRE) are ubiquitous regulator of inflammatory and immunological reactions [8]. CRE is expressed in a wide variety of cell types. It has been established that cAMP induces phosphorylation of CRE, which then activates cAMP-responsive genes, leading to increased cell proliferation, differentiation, or modulation of various cell functions [9]. TLR2 found to be mediated by cAMP production [8]. CRE-like sequence (TGACGTCA) is detected at two positions in both B. taurus and Vechur sequence. First, CRE is positioned at -379 to -372 bp with one SNP at bp -375 in both Vechur cattle and B. taurus, and second, CRE is positioned at -470 to $-463 \mathrm{bp}$ is observed with three mismatch base pair in Vechur and two mismatch base pair in B. taurus.

Nuclear factor-kappa B (NF-kB) transcription factor was observed at position -440 to $-431 \mathrm{bp}$ with two mismatch base pairs in both Vechur and B. taurus sequence with reference consensus sequence. NF-kB consists of a family of transcription factor that play critical roles in inflammation, immunity, cell proliferation, differentiation, and survival [10]. This NF-kB plays an important role in the regulation of TLR2 gene expression [11]. The special protein binding sites (Sp site), which enhance the expression of TLR2 gene [12] is also present in the region between -571

Table-3: Important sequence motifs and variants observed in the TLR2 promoter region of $B$. taurus and Vechur cattle breed.

\begin{tabular}{|c|c|c|c|c|}
\hline Motif & Consensus sequence & Region & B.taurus sequence & Vechur sequence \\
\hline TATA sequence & TATA & $\begin{array}{c}-726 \text { to }-723 \\
-85 \text { to } 81 \\
-752 \text { to }-748\end{array}$ & $\begin{array}{l}\text { TATA } \\
\text { TATAA } \\
\text { TATAA }\end{array}$ & $\begin{array}{l}\text { TATA } \\
\text { TATAA } \\
\text { TECTAA }\end{array}$ \\
\hline CRE & TGACGTCA & $\begin{array}{l}-379 \text { to }-372 \\
-470 \text { to }-463\end{array}$ & $\begin{array}{l}\text { TGACITCA } \\
\text { TGAATTCA }\end{array}$ & $\begin{array}{l}\text { TGACITCA } \\
\text { TGGATTCA }\end{array}$ \\
\hline E-box & CANNTTG & -200 to -195 & CATATG & CATATG \\
\hline EC & GTGG $(A / T)(A / T)(A / T)$ & -645 to -639 & GTGGAAA & GTGGAAA \\
\hline CAAT & CAAT & -11 to -8 & CAAT & CAAT \\
\hline NF-kB & GGGRNNYYCC, R-purine, Y-pyrimidine & -440 to -431 & GGGAAATATC & GGGAAATATC \\
\hline & GAAANNGAAAGG & -73 to -62 & GAAAGAGAAAAA & GAAAGAGAAAAA \\
\hline Sp-1 site & GGGCGG & -571 to -567 & AGGCG & $\underline{\mathbf{G G G C G}}$ \\
\hline
\end{tabular}

$\mathrm{EC}=$ Enhancer core, $\mathrm{TLR}=$ Toll-like receptor, $\mathrm{CRE}=\mathrm{Cyclic}$ adenosine monophosphate responsive elements, NF-kB=Nuclear factor-kappa B, IRF=Interferon regulatory factor 3 , B. taurus $=$ Bos taurus 
and -567 bp in Vechur, whereas B. taurus reveals one mismatch at $-571 \mathrm{bp}$.

In the present study, the sequence of the promoter region of TLR 4 of Vechur cattle revealed $99 \%$ similarity with that of $B$. taurus sequence and had important motifs such as TATA, CAAT, E-box, NF-kB, CRE, and $\mathrm{CpG}$ regions required for regulation of transcription but not reveals significant variant in motif regions. The important sequence motif for TLR4 observed in Vechur cattle with that of B. taurus sequence are

\begin{tabular}{|c|c|c|}
\hline $\begin{array}{l}\text { Vechur } \\
\text { Hereford }\end{array}$ & $\begin{array}{r}--- \text { CAGGAGTTTGTAAGAGAACCCACCCTTGGGTTICCCAAGGACTAAAACCTATTAT } \\
\text { CAGGAGTTTGTAAGAGAGAAGAACCCACCCTTGGGTTCCCAAGGACTAAAACCTATTAT } \\
*\end{array}$ & -778 \\
\hline $\begin{array}{l}\text { Vechur } \\
\text { Hereford }\end{array}$ & 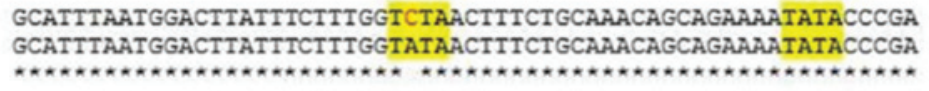 & -718 \\
\hline $\begin{array}{l}\text { Vechur } \\
\text { Hereford }\end{array}$ & $\begin{array}{l}\text { GATCCCCACTAGGACCCATAACACAAAAATGTTCATTIACAAACCATAATATCTAATGAG } \\
\text { GATCCCCACTAGGACCCATAACACAAAAATGITCATTIACAAACCATAATATCTAATGAG } \\
\end{array}$ & -658 \\
\hline $\begin{array}{l}\text { Vechur } \\
\text { Hereford }\end{array}$ & 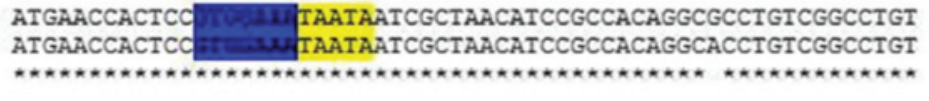 & -598 \\
\hline $\begin{array}{l}\text { Vechur } \\
\text { Hereford }\end{array}$ & 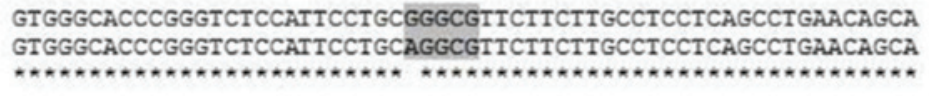 & -538 \\
\hline $\begin{array}{l}\text { Vechur } \\
\text { Hereford }\end{array}$ & 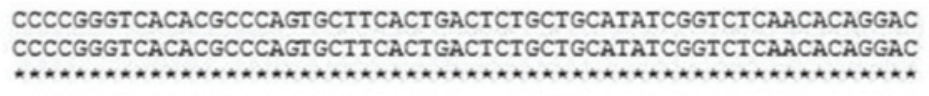 & -478 \\
\hline $\begin{array}{l}\text { Vechur } \\
\text { Hereford }\end{array}$ & $\begin{array}{l}\text { CCTCTGATGGATTCATIACTGCCCTGTCTITGTGACA ECGAATATGIGCGGTCAGACCG } \\
\text { CCTCTGATGAATICATIACTGCCCTGTCTTTGTGACA }\end{array}$ & -418 \\
\hline $\begin{array}{l}\text { Vechur } \\
\text { Hereford }\end{array}$ & 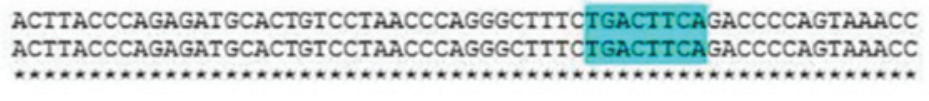 & -358 \\
\hline $\begin{array}{l}\text { Vechur } \\
\text { Hereford }\end{array}$ & $\begin{array}{l}\text { ACACAGACCCAGTTCTGGCTGAAGATGAAGCAAGGTCACTTCCTTCACACATGGTICCCA } \\
\text { ACACAGACCCAGTTCTGGCTGAAGATGAAGCAAGGTCACTICCTTCACACATGGTICCCA }\end{array}$ & -298 \\
\hline $\begin{array}{l}\text { Vechur } \\
\text { Hereford }\end{array}$ & 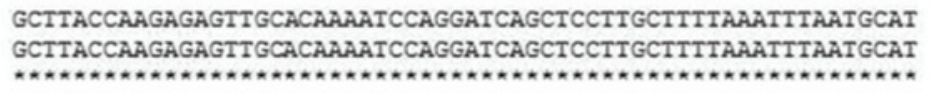 & -238 \\
\hline $\begin{array}{l}\text { Vechur } \\
\text { Hereford }\end{array}$ & 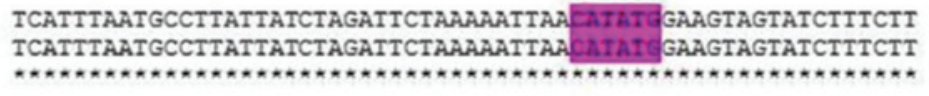 & -178 \\
\hline $\begin{array}{l}\text { Vechur } \\
\text { Hereford }\end{array}$ & 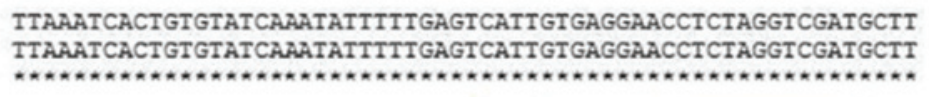 & -118 \\
\hline $\begin{array}{l}\text { Vechur } \\
\text { Hereford }\end{array}$ & $\begin{array}{l}\text { GCTTAAAAATTIATTIAGCTCACACATACTTCTATAACATTICA GAAAGAGAAAMA GAGG } \\
\text { GCTTAAAAATTIATTTAGCTCACACATACTICTATAACATITCAGAAAGAGAAAAA GAGA }\end{array}$ & -58 \\
\hline $\begin{array}{l}\text { Vechur } \\
\text { Hereford }\end{array}$ & $\begin{array}{l}\text { GCCCTTTTTAGAATTAGAAACAAGACTTTTTAAAAGAAGGAAAAAGCAATATGATTC } \\
\text { GCCCTITTIAGAATTAGAAACAAGACTTTITAAAAGAAGGAAAAAGCAATATGATTC } \\
\end{array}$ & -1 \\
\hline
\end{tabular}

Figure-2: Sequence alignment of toll-like receptor 2 promoter region of Vechur cattle breed and Bos taurus (Hereford) highlighted with important motifs.

Table-4: Important sequence motifs and variants observed in the TLR4 promoter region of $B$. taurus and Vechur cattle breed.

\begin{tabular}{lllll}
\hline Motif & Consensus sequence & Region & $\begin{array}{l}\text { Bos taurus } \\
\text { sequence }\end{array}$ & $\begin{array}{l}\text { Vechur } \\
\text { sequence }\end{array}$ \\
\hline TATA & TATA & -513 to- 510 & TATA & TATA \\
E-box & CANNTTG & -101 to-98 & CATGTG & CATGTG \\
CRE & TGACGTCA & -823 to-818 & TGACGTGA & TGACGTGA \\
CAAT & CAAT & -17 to-10 & CAAT \\
NF-kB & GGGRNNYYCC, R-purine, Y-pyrimidine & -732 to-729 & CAAT & to-226 \\
Sp-1 site & GGGCGG & -92 to-81 & GGGTGGCICI & GGGTGGCICI \\
\hline
\end{tabular}

$\mathrm{EC}=$ Enhancer core, $\mathrm{TLR}=$ Toll-like receptor, $\mathrm{CRE}=$ Cyclic adenosine monophosphate responsive elements, NF-kB=Nuclear factor-kappa B, B. taurus=Bos taurus 
listed in Table-4 and highlighted in Figure-3. TLR4 plays an important role in the induction of the inflammatory response by recognizing exogenous PAMPs and endogenous ligands [13]. TLR4 is linked to the activation of NF- $\kappa \mathrm{B}$ factor in several cell types [14]. Increased NF- $\mathrm{KB}$ activity was found in the milk and intra-mammary epithelial cells of mastitis-affected cows. Although Vechur promoter sequence of TLR4 did not show any polymorphism with $B$. taurus sequence, however, chromatograph reveals two heterozygous conditions in Vechur breed (Figure-4).

Promoter sequence of TLR9 gene also showed $99 \%$ similarity to B. taurus sequence and revealed variants for four sequence motifs. The sequence variation in TLR9 promoter region for the important motifis presented in Table-5 and Figure-5. TLR9, which is localized intracellularly, is involved in the recognition of specific unmethylated $\mathrm{CpG}$-oligodeoxynucleotides (ODN) sequences that distinguish bacterial DNA from mammalian DNA. Bacterial DNA can stimulate immune cells mainly because of the unmethylated $\mathrm{CpG}$ motifs, which are rarely detected in vertebrate DNA, and if present, are highly methylated. Species difference in TLR9 expression during mastitis exists as CpG-ODN has been shown to promote the expression of its specific receptor (TLR9 mRNA) in goat mammary tissue [15].

The promoter sequence of TLR9 in Vechur and B. taurus shows variation for enhancer core (EC) region, CAAT box, nuclear factor-kappa binding protein, and $\mathrm{Sp}-1$ binding site. EC region is expressed in a variety of tissues, and transgenic animal studies have demonstrated that EC region plays a critical role in thymocyte and macrophage development [16]. Three $\mathrm{EC}$ regions were observed in the sequence of Vechur

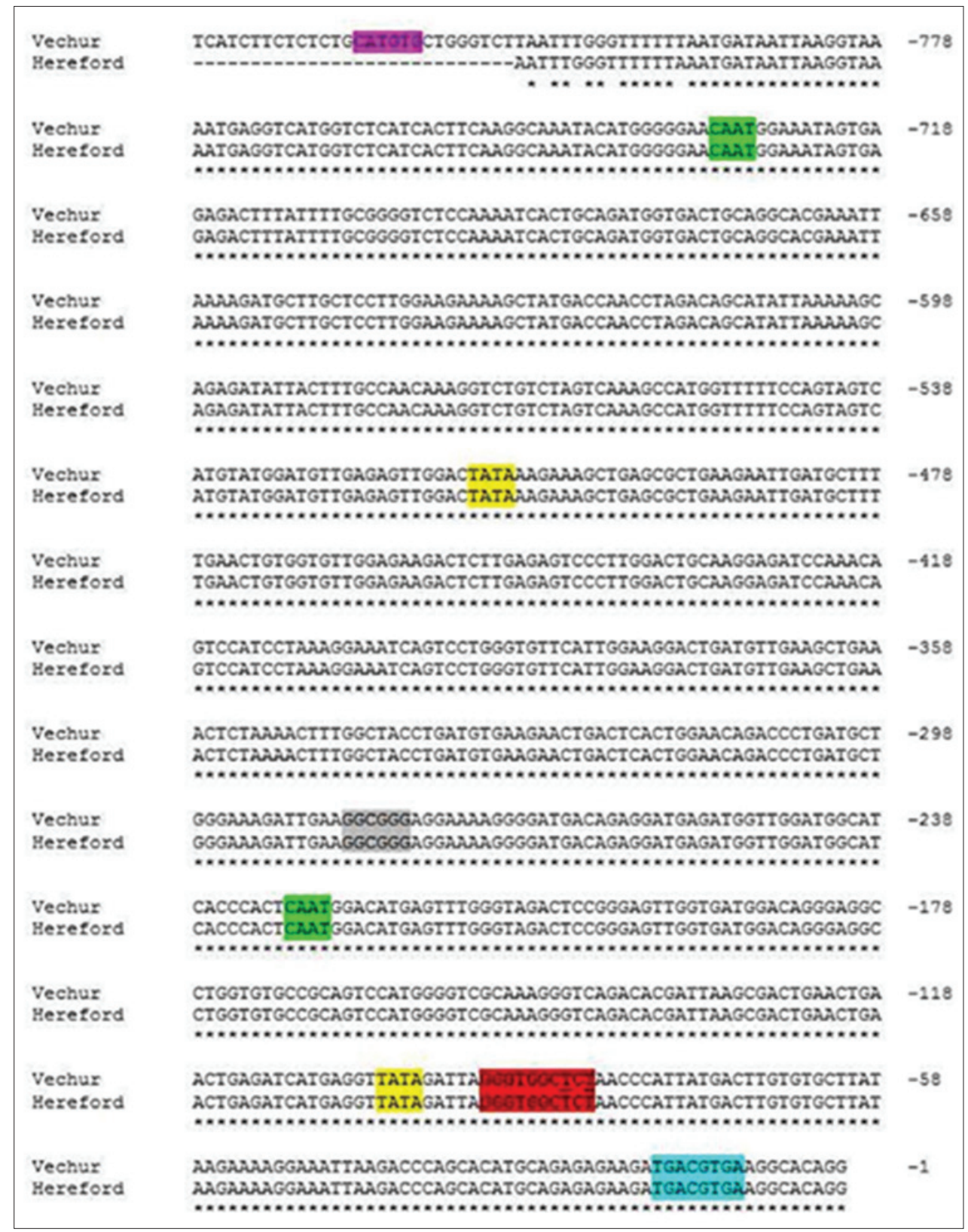

Figure-3: Sequence alignment of toll-like receptor 4 promoter region of Vechur cattle breed and Bos taurus (Hereford) highlighted with important motifs. 
cattle. CAAT box region also found in Vechur, however, B. taurus sequence reveals variation for this box at $-307 \mathrm{bp}$. ECs, CAAT enhancer binding protein might physically and functionally interact with each other, leading to maximal transcription of the TLR9 gene [17].

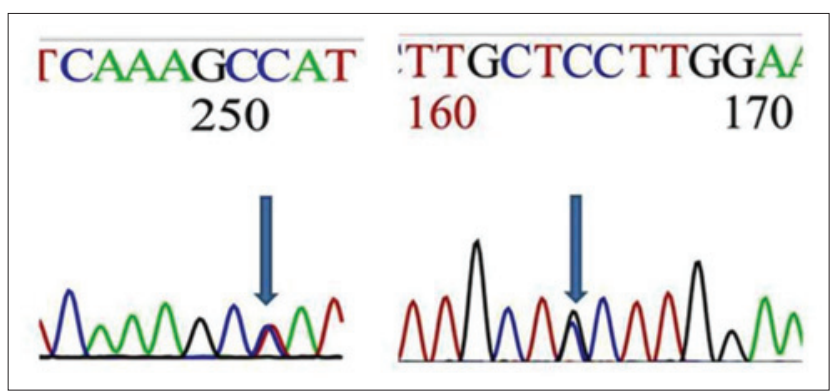

Figure-4: Sequence chromatographs reveal heterozygous peaks in the promoter region of toll-like receptor 4 gene.
$\mathrm{NF}-\mathrm{kB}$ was observed at three positions; one SNP was observed in both Vechur and B. taurus at $-307 \mathrm{bp}$, respectively. Vechur sequence also reveals another SNP in the NF-kB region of $-61 \mathrm{bp}$. Sp1 binding sites were noticed at two regions, no variation was observed between Vechur and consensus sequence for this binding sites, however, $B$. taurus reveals an SNP at $-403 \mathrm{bp}$.

\section{Conclusion}

The TLR2 and TLR9 promoter regions are considerably more variable than TLR4 in Vechur breed to that of B. taurus as revealed by four different important motifs which further identified with SNPs. TATA and CAT boxes and multiple putative binding sites present in the TLR2 and TLR9 promoter sequences may influence the transcription. This study is, therefore, the first to propose that genetic variation in the

\begin{tabular}{|c|c|c|}
\hline $\begin{array}{l}\text { Vechur } \\
\text { Hereford }\end{array}$ & $\begin{array}{l}\text { ATGTGTGACGAGAGATGICAGGTGGGTGAGGGAGGGGGCCGTGIGAGTATCTGGAAAAAG } \\
\text { ATGTGTGACGAGAGATGICAGGTGGGTGAGGGAGGGGGCCGTGTGAGIATCTGGAAAAAG }\end{array}$ & -758 \\
\hline $\begin{array}{l}\text { Vechur } \\
\text { Hereford }\end{array}$ & $\begin{array}{l}\text { AGCTICAAGACACAGGGAACAGTATGITCAAAGGCCCTGGGGCAGGAGAATTACATGEAI } \\
\text { AGCTTCAAGACACAGGGAACGGTATGTTCAAAGGCCCTGGGGCAGGAGATTACATGCA1 }\end{array}$ & -698 \\
\hline $\begin{array}{l}\text { Vechur } \\
\text { Hereford }\end{array}$ & 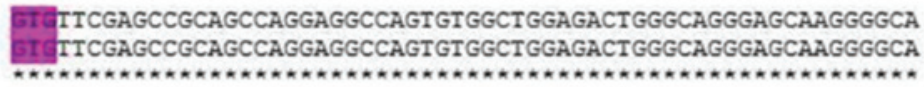 & -638 \\
\hline $\begin{array}{l}\text { Vechur } \\
\text { Hereford }\end{array}$ & 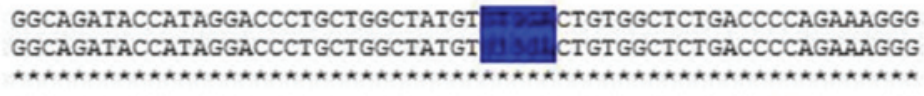 & -578 \\
\hline $\begin{array}{l}\text { Vechur } \\
\text { Hereford }\end{array}$ & $\begin{array}{l}\text { CCATGGAGGGGTCTGAGCAGAGAAGGGACCTAATGTGACTIAGGGGCCTAATAAGAACAA } \\
\text { CCATGGAGGGGTCTGAGCAGAGAAGGGACCTAATGTGACTTAGGGGCCTAATAAGAACAA }\end{array}$ & -518 \\
\hline $\begin{array}{l}\text { Vechur } \\
\text { Hereford }\end{array}$ & 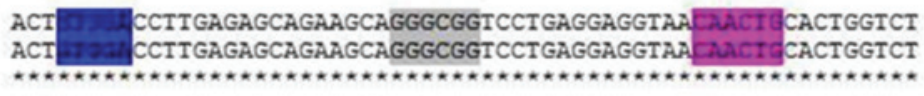 & -458 \\
\hline $\begin{array}{l}\text { Vechur } \\
\text { Hereford }\end{array}$ & 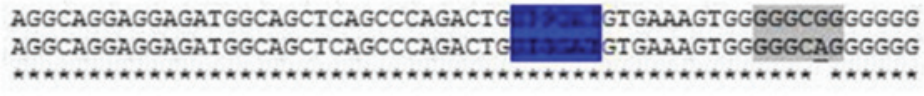 & -398 \\
\hline $\begin{array}{l}\text { Vechur } \\
\text { Hereford }\end{array}$ & $\begin{array}{l}\text { AAAATGGGCAGATTCTGAACATGGAGCCAGCAGGACTIGCTGAGGGTCCCGGGGCAACCT } \\
\text { AAAATGGGCAGATTCTGAACATGGAGCCAGCAGGACTIGCTGAGGGICCCGGGGCAACCT }\end{array}$ & -338 \\
\hline $\begin{array}{l}\text { Vechur } \\
\text { Hereford }\end{array}$ & 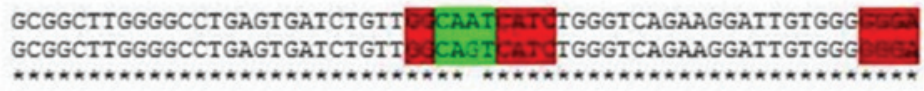 & -278 \\
\hline $\begin{array}{l}\text { Vechur } \\
\text { Hereford }\end{array}$ & $\begin{array}{l}\text { DCTAGGGGAGGATGAGCCAGGAGGTCTCAGCTGATCCAGCGGTGGGGTITGTGCTCTG } \\
\text { DCTCAGGGGAGGATGAGCCAGGAGGTCTCAGCTGATCCAGTGGTGGGGITGTGCTCTG }\end{array}$ & -218 \\
\hline $\begin{array}{l}\text { Vechur } \\
\text { Hereford }\end{array}$ & $\begin{array}{l}\text { ATGGTGCTCTGGGGATGCAGAGGAGGGCCTGCTCCTGGAGGAAGCTGCCGCTGTGGCAGG } \\
\text { ATGGTGCTCTGGGGATGCAGAGGAGGGCCTGCTCCTGGAGGAAGCTGCCGCTGTGGCAGG }\end{array}$ & -158 \\
\hline $\begin{array}{l}\text { Vechur } \\
\text { Hereford }\end{array}$ & $\begin{array}{l}\text { GGCAGATGACCCTGGGCAAGGCCAGTGCTGCCCCCIGCCCCATACGCCAGGCCTGGCATG } \\
\text { GGCAGATGACCCTGGGCAAGGCCAGTGCTGCCCCCTGCCCCATACGCCAGGCCTGGCATG }\end{array}$ & -98 \\
\hline $\begin{array}{l}\text { Vechur } \\
\text { Hereford }\end{array}$ & 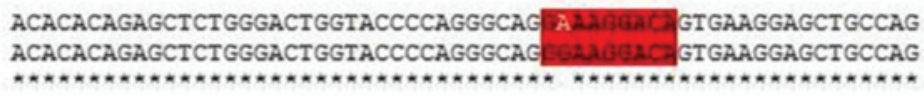 & -38 \\
\hline $\begin{array}{l}\text { Vechur } \\
\text { Hereford }\end{array}$ & $\begin{array}{l}\text { CCTGAGACTGCTGCCTGGGGGGGCAGGGGCTGAGAAG } \quad-1 \\
\text { CCTGAGACTGCTGCCTGGGGGGGCAGGGGCTGAGAAG }\end{array}$ & \\
\hline
\end{tabular}

Figure-5: Sequence alignment of toll-like receptor 9 promoter region of Vechur cattle breed and Bos taurus (Hereford) highlighted with important motifs. 
Table-5: Important sequence motifs and variants observed in the TLR9 promoter region of $B$. taurus and Vechur cattle breed.

\begin{tabular}{|c|c|c|c|c|}
\hline Motif & Consensus sequence & Region & $\begin{array}{l}\text { B. taurus } \\
\text { sequence }\end{array}$ & $\begin{array}{l}\text { Vechur } \\
\text { sequence }\end{array}$ \\
\hline TATA sequence & TATA & -529 to -525 & TEATA & T吕ATA \\
\hline E-box & CANNTTG & $\begin{array}{c}-700 \text { to }-695 \\
-72 \text { to }-467\end{array}$ & $\begin{array}{l}\text { CATGTG } \\
\text { CAACTG }\end{array}$ & $\begin{array}{l}\text { CATGTG } \\
\text { CAACTG }\end{array}$ \\
\hline EC & GTGG $(A / T)(A / T)(A / T)$ & $\begin{array}{l}-606 \text { to }-602 \\
-514 \text { to }-510 \\
-424 \text { to }-419\end{array}$ & $\begin{array}{l}\text { GTGGA } \\
\text { GTGGA } \\
\text { GTGGAT }\end{array}$ & $\begin{array}{l}\text { GTGGA } \\
\text { GTGGA } \\
\text { GTGGAT }\end{array}$ \\
\hline CAAT & CAAT & -309 to -306 & CAG & CAAT \\
\hline NF-kB & $\begin{array}{l}\text { GGGRNNYYCC, R-purine, } \\
\text { Y-pyrimidine }\end{array}$ & $\begin{array}{l}-281 \text { to }-271 \\
-311 \text { to }-302 \\
-62 \text { to }-54\end{array}$ & $\begin{array}{l}\text { GGGAGCCTC } \\
\text { GGCAGTCATC } \\
\text { GGAAGGACA }\end{array}$ & $\begin{array}{l}\text { GGGAGCCTC } \\
\text { GGCAATCATC } \\
\text { GAAAGGACA }\end{array}$ \\
\hline Sp-1 site & GGGCGG & $\begin{array}{l}-492 \text { to }-487 \\
-408 \text { to }-402\end{array}$ & $\begin{array}{l}\text { GGGCGG } \\
\text { GGGGCAG }\end{array}$ & $\begin{array}{l}\text { GGGCGG } \\
\text { GGGGCGG }\end{array}$ \\
\hline
\end{tabular}

$\mathrm{EC}=$ Enhancer core, $\mathrm{TLR}=$ Toll-like receptor, NF-kB=Nuclear factor-kappa $\mathrm{B}, \mathrm{B}$. taurus $=$ Bos taurus

TLRs promoter might influence the TLRs expression. A significant finding is the identification of SNPs in the promoter of TLR2 and 9 genes in Vechur cattle breed. The variation in TLR promoter sequence of Vechur breed might potentially influence the innate immunity response against mastitis.

\section{Authors' Contributions}

$\mathrm{RL}$ - The research work mentioned in this article is a part of the Ph.D. research work of the first author and first author carried out all the work mentioned in this article. KKJ - The entire work mentioned in this article was carried out under the guidance and supervision of the second author. TVA- Member of research advisory committee reviewed the manuscript. All authors read and approved the final manuscript.

\section{Acknowledgments}

The first author acknowledging the INSPIRE Fellowship program of Department of Science and Technology, Ministry of Science and Technology, Government of India, for providing fellowship for the Ph.D. program. The authors are thankful to the Dean, College of Veterinary and Animal Science, for providing facilities to conduct this experiment.

\section{Competing Interests} interests.

The authors declare that they have no competing

\section{References}

1. Uematsu, S. and Akira, S. (2006) Toll-like receptors and innate immunity. J. Mol. Med., 84: 712-725.

2. Akira, S. and Hemmi, H. (2003) Recognition of pathogen associated molecular patterns by TLR family. Immonol. Lett., 85: 85-95.

3. Fernando, N., Eduardo, M.R.S., Marcos, B.H., Magnus, A.G., Luiza, C.R., Maiara, G.B. and Alice, M.M. (2012) The innate immunity in ovine mastitis: The role of pattern-recognition receptors. Am. J. Immunol., 8: 166-178.

4. Tanaka, J., Sugimoto, K., Shiraki, K., Tameda, M., Kusagawa, S., Nojiri, K., Beppu, T., Yoneda, K., Yamamoto, N., Uchida, K., Kojima, T. and Takei, Y. (2010)
Functional cell surface expression of toll-like receptor 9 promotes cell proliferation and survival in human hepatocellular carcinomas. Int. J. Oncol., 37: 805-814.

5. Hogeveen, H., Huijps, K. and Lam, T.J.G. (2011) Economic aspects of mastitis: New developments. N. Z. Vet. J., 59: 16-23.

6. Muhaghegh-Dolatabady, H. and Habibizad, J. (2014) Sequence characterization of promoter region at the melanocortin-1 receptor (MC1R) gene in karakul sheep breed. J. Agric. Sci. Technol., 16: 551-560.

7. Viola, H., Lucia, S., Matthew, J.F. and Michal, R. (2002) Transcription regulation of the human toll-like receptor 2 gene in monocytes and macrophages. J. Immunol., 168: 5629-5637.

8. Eun, Y.M., Yu, S.L., Wahn, S.C. and Mi, H.L. (2011) Tolllike receptor 4 mediated cAMP production upregulates B-cell activating factor expression in raw264.7 macrophages. Sci. Direct, 317: 2447-2455.

9. Blobel, G.A. (2000) CREB-binding protein and p300: Molecular integrators of hematopoietic transcription. Blood, 95: 745.

10. Oeckinghaus, A. and Ghosh, S. (2009) The NF-kB family of transcription factors and its regulation. Cold Spring Harb. Perspect. Biol., 1: 1-14.

11. Musikacharoen, T., Matsuguchi, T., Kikuchi, T. and Yoshikai, Y. (2001) NF-kB and STAT5 play important roles in the regulation of mouse toll-like receptor 2 gene expression. J. Immunol., 166: 4516-4524.

12. Haehnel, V., Schwarzfischer, L., Fenton, M.J. and Rehli, M. (2002) Transcription regulation of the human toll-like receptor 2 gene in monocytes and macrophages. J. Immunol., 168: 5629-5637.

13. Miyake, K. (2007) Innate immune sensing of pathogens and danger signals by cell surface toll-like receptors. Semin. Immunol., 19: 3-10.

14. Kuhn, H., Petzold, K., Hammerschmidt, S. and Wirtz, H. (2014) Interaction of cyclic mechanical stretch and toll-like receptor 4-mediated innate immunity in rat alveolar Type II cells. Respirology, 19: 67-73.

15. Zhu, Y.M., Miao, J.F., Zhang, Y.S., Li, Z., Zou, S.X. and Deng, Y.E. (2007) CpG ODN enhances mammary gland defense during mastitis induced by Escherichia coli infection in goats. Vet. Immunol. Immunopathol., 120: 168-176.

16. Zaldumbide,A., Carlotti, F., Pognonec, P. and Boulukos, K.E. (2002) The role of the Ets2 transcription factor in the proliferation, maturation, and survival of mouse thymocytes. $J$. Immunol., 169: 4873.

17. Takeshita, F., Leifer, C.A., Gursel, I., Iashii, K.L., Takeshita, S., Gursel, M. and Klinman, D.M. (2001) Transcriptional regulation of the human TLR9 gene. J. Immunol., 173: 2552-2561.

\section{$* * * * * * * *$}

